\title{
Downregulation of uPA/uPAR inhibits intermittent hypoxia-induced epithelial-mesenchymal transition (EMT) in DAOY and D283 medulloblastoma cells
}

\author{
RESHU GUPTA ${ }^{1}$, CHANDRAMU CHETTY ${ }^{1}$, PRAVEEN BHOOPATHI ${ }^{1}$, SAJANI LAKKA ${ }^{1}$, \\ SANJEEVA MOHANAM ${ }^{1}$, JASTI S. RAO ${ }^{1,2}$ and DZUNG H. DINH ${ }^{2}$ \\ Departments of ${ }^{1}$ Cancer Biology and Pharmacology, and ${ }^{2}$ Neurosurgery, \\ University of Illinois College of Medicine at Peoria, Peoria, IL 61605, USA
}

Received September 8, 2010; Accepted October 13, 2010

DOI: $10.3892 /$ ijo.2010.883

\begin{abstract}
Hypoxia is known to induce overexpression of the urokinase plasminogen activator ( $\mathrm{UPA}$ ) and its receptor (UPAR) and thus overexpression promotes uPAR-mediated survival signaling in various cancers. Moreover, hypoxia/ overexpression of UPAR in cancer cells promote the epithelialmesenchymal transition (EMT) and thereby invasiveness and metastasis. In this study, we show that intermittent hypoxia has a more pronounced effect than chronic hypoxia and contributes to EMT, invasion and migration in medulloblastoma cells. Intermittent hypoxia induced expression of mesenchymal markers (i.e., SNAIL, Vimentin and N-cadherin) and reduced expression of epithelial markers (i.e., Zo-1, E-cadherin) in medulloblastoma cells. Further, intermittent hypoxia also leads to enhancement in cell invasion, migration and angiogenesis in medulloblastoma cells. Intermittent hypoxia also inhibited expression of pro-anti-apoptotic proteins (Bax and Bad), and induced expression of anti-proapoptotic proteins ( $\mathrm{Bcl} 2$ and $\mathrm{Bcl}-\mathrm{xL})$, and activation of ERK in medulloblastoma cells. Transcriptional inactivation of either UPA or UPAR inhibits the intermittent hypoxia-induced invasion and migration, and expression of Vimentin. uPA/ uPAR downregulation also induces E-cadherin expression and inhibits activation of ERK. Thus, transcriptional inactivation of either UPA or UPAR enhances the apoptotic response in medulloblastoma cells exposed to intermittent hypoxia. This study provides evidence of the anti-tumor efficacy of downregulation of UPA or UPAR in medulloblastoma tumors to target hypoxia-induced cell EMT, invasion and migration, to achieve better therapeutic outcomes in the treatment of malignant medulloblastoma.
\end{abstract}

Correspondence to: Professor Dzung H. Dinh, Department of Neurosurgery, University of Illinois College of Medicine at Peoria, One Illini Drive, Peoria, IL 61605, USA

E-mail: ddinh@uic.edu

Key words: hypoxia, epithelial-mesenchymal transition, cell cycle, apoptosis, angiogenesis, uPA, uPAR

\section{Introduction}

Medulloblastoma is the most common, rapidly-growing tumor of the cerebellum that arises in childhood, and it has a tendency to metastasize via the cerebrospinal fluid (CSF) pathway (1). In addition to surgical resection, post-operative radiotherapy and chemotherapy are the mainstays in treating patients with medulloblastoma (2). However, these tumors remain among the most challenging pediatric brain tumors. Factors related to the tumor microenvironment are being recognized as fundamental to tumor progression, metastasis and increased resistance to radiation and chemotherapy. Hypoxia is one factor that leads to epigenetic and genetic adaptation in tumor cells, which in turn, increases invasiveness and metastasis. Thus, this hypoxic environment is tightly associated with tumorigenesis and may provide tumors with the ability to outgrow the existing vasculature.

Under hypoxic conditions, the transcription factor hypoxia inducible factor- $1 \alpha$ (HIF-1 $\alpha)$ dimerizes with HIF-1ß and triggers many hypoxia-associated changes in cell physiology, including angiogenesis; constitutive expression of HIF- $1 \alpha$ renders tumor cells resistant to hypoxia (3). While chronic or diffusion-limited hypoxia leads to limitations in blood perfusion due to temporary closure of blood vessels, intermittent hypoxia could positively modulate tumor development, angiogenesis and chemo- and radio-resistance. Previous studies have shown the effects of intermittent hypoxia to be more potent than those of chronic hypoxia $(4,5)$. In turn, these hypoxic adaptations make the tumors more difficult to treat and represent an independent indicator of poor prognosis in diverse human malignancies, including breast cancer, head and neck cancer, prostate cancer, brain tumors and malignant melanoma (6).

In cancer, epithelial-mesenchymal transition (EMT) may be an important step leading to invasion and metastasis (7). It has been shown that hypoxia induces EMT in cancer cells by increasing expression of the urokinase plasminogen activator receptor (UPAR) and by activating UPAR-dependent cell signaling (8), thereby making it a potential biological marker correlated to tumor progression and aggressiveness $(9,10)$. uPAR has two distinct ligands that activate different cell signaling pathways. Binding of urokinase plasminogen 
activator (UPA) to uPAR activates ERK1/2 and PI3-K which in turn activates Rac1 and promotes cell migration. Mounting evidence suggests that hypoxia may initiate metastasis in cancer cells. Adopting a metastatic phenotype may occur as a result of uPAR activation in conjunction with EMT, or it may involve other receptors, such as the erythropoietin receptor or the receptor for hepatocyte growth factor/Met tyrosine kinase $(11,12)$. Previous studies have shown that $\alpha 3$ integrins and uPAR cooperate to induce phenotypic changes consistent with EMT $(13,14)$. Since these studies suggest a relationship between tumor hypoxia and EMT, our objective was to increase understanding of this link.

In the present study, we demonstrate that intermittent hypoxia induces diverse molecular and phenotypic changes that are consistent with EMT in medulloblastoma cells. We also show that cell signaling molecules, which are thought to be involved in EMT (Vimentin, N-cadherin, SNAIL), are overexpressed in medulloblastoma cells exposed to intermittent hypoxic conditions (18 cycles: one cycle composed of $48 \mathrm{~h}$ at $1 \% \mathrm{O}_{2}$ followed by $48 \mathrm{~h}$ at $21 \% \mathrm{O}_{2}$ ), while less expression of epithelial markers (Zo-1 and E-cadherin) have been observed in these cells when compared with normoxic cells and chronic hypoxic cells (normoxic cells exposed to $48 \mathrm{~h}$ of hypoxia). We found enhanced expression of uPA and uPAR in hypoxic-conditioned cells in comparison to normoxic cells and normoxic cells exposed to $48 \mathrm{~h}$ of hypoxia. Therefore we target intermittent hypoxic-conditioned cells only for further si-RNA-based approach. For this we used siRNA against either uPA/uPAR to downregulate uPA (pU) or uPAR (pUR), respectively, and showed that intermittent hypoxia-induced uPAR-mediated EMT was inhibited effectively by uPA/ uPAR siRNA in medulloblastoma cells.

This study demonstrates that the intermittent hypoxiainduced uPA and UPAR expression is inducing EMTassociated phenotypic changes and cell signaling molecules, and activation of uPAR-dependent cell survival signaling activation, which has been suppressed by plasmid vectormediated delivery of uPA/uPAR siRNA. These results strongly support that therapeutic targeting of uPA/uPAR by $\mathrm{pU}$ and pUR, respectively, has more pronounced effect on suppressing intermittent hypoxia-induced EMT, migration and invasion in medulloblastoma cells.

\section{Materials and methods}

Antibodies and reagents. The antibodies used in this study are phosphorylated ERK, human uPAR, Vimentin, E-cadherin, N-cadherin, Bcl-2, Bad, Bcl-xL, Bax, human uPA, SNAIL (Santa Cruz Biotechnology, Santa Cruz, CA); HIF-1 $\alpha$, (Novus Biologicals, Littleton, CO, USA), GAPDH Cell Signaling, Boston, MA) and HRP-conjugated secondary antibodies (Biomed, Foster City, CA). The TRIzol reagent (Life Technologies, Carlsbad, CA), reverse transcription kit (Roche Diagnostics, Indianapolis, IN), MTT reagent (Sigma, St. Louis, MO), were also used in this study.

Cell cultures. DAOY cells were obtained from ATCC and cultured in advanced-MEM while D283 cells were cultured in Zinc Option media supplemented with $5 \%$ fetal bovine serum, $2 \mathrm{mM} / \mathrm{l} \mathrm{L}$-glutamine, $100 \mathrm{U} / \mathrm{ml}$ of each penicillin, and
$100 \mu \mathrm{g} / \mathrm{ml}$ streptomycin. Cells were maintained in a humidified atmosphere containing $5 \% \mathrm{CO}_{2}$ at $37^{\circ} \mathrm{C}$. All hypoxic experiments were carried out in Hypoxic chamber (Model no. C-474, Biospherex, Lacona, NY) in which $\mathrm{O}_{2}$ level was maintained at $1 \%$.

Generation of intermittent hypoxic-conditioned DAOY/D283 cells. Intermittent hypoxic-conditioned (H) DAOY/D283 cells were derived by being exposed to hypoxia $\left(1 \% \mathrm{O}_{2}\right)$ and reoxygenation $\left(21 \% \mathrm{O}_{2}\right)$ cycles (18-20 cycles). Each cycle consisted of a period of $48 \mathrm{~h}$ in hypoxia followed by $48 \mathrm{~h}$ of recovery under normoxic conditions. Parental or Normal DAOY/D283 $(\mathrm{N})$ cells given $48 \mathrm{~h}$ of continuous hypoxia considered as chronic hypoxic cells.

Reverse transcription PCR. Total RNA was extracted using TRIzol reagent (Life Technologies) as per the manufacturer's instructions. RT-PCR was done using a reverse transcription kit (Roche Diagnostics). PCR products were resolved on agarose gels (2\%) and visualized by ethidium bromide staining. GAPDH was used as a loading control. PCR was performed using the following primers: HIF-1 $\alpha$ forward 5'-AGTCTGC AACATGGAAGG-3' and reverse 5'-CACGACTTGATTT TCTCCC-3' and GAPDH forward 5'-TGAAGGTCGGAGTC AACGGATTTGGT-3' and reverse 5'-CATGTGGGCCATG AGGTCCACCAC-3'.

Western blot analysis. Control (N; normal) and intermittent hypoxic-conditioned $(\mathrm{H}) \mathrm{DAOY} / \mathrm{D} 283$ cells were cultured and maintained in $21 \% \mathrm{O}_{2}$ and $1 \% \mathrm{O}_{2}$. Cell extracts were prepared in ice-cold RIPA buffer [50 mmol/1 Tris- $\mathrm{HCl}$ (pH 7.4), $150 \mathrm{mmol} / \mathrm{l} \mathrm{NaCl}, 1 \%$ IGEPAL, $1 \mathrm{mmol} / \mathrm{l}$ EDTA, $0.25 \%$ sodium deoxycholate, $1 \mathrm{mmol} / 1$ sodium fluoride, $1 \mathrm{mmol} / \mathrm{l}$ sodium orthovanadate, $0.5 \mathrm{mmol} / 1 \mathrm{PMSF}, 10 \mu \mathrm{g} / \mathrm{ml}$ aprotinin, and $10 \mu \mathrm{g} / \mathrm{ml}$ leupeptin]. Equal amounts of proteins were subjected to SDS-PAGE and were transferred to nitrocellulose membranes and probed with primary antibodies to detect HIF-1 $\alpha$, phosphorylated ERK, human uPA, human uPAR, Vimentin, E-cadherin, N-cadherin, Bcl-2, Bad, Bcl-xL, Bax and SNAIL. The same membranes were reprobed to detect GAPDH as a loading control.

MTT proliferation assay. Cells were grown in $100-\mathrm{mm}$ petri plates and were serum-starved for $12 \mathrm{~h}$. Cells were trypsinized, counted and seeded at $2 \times 10^{4}$ cells per well in 96-well plates (12 replicates per group). The normal $(\mathrm{N})$ and intermittent hypoxic-conditioned $(\mathrm{H})$ cells were kept in both normoxic and hypoxic conditions. After the indicated period of incubation, $20 \mu 1$ of MTT reagent were added to the cells and followed by another $4 \mathrm{~h}$ of incubation at $37^{\circ} \mathrm{C}$. DMSO was added to all wells and mixed vigorously so that the formazan crystals dissolved effectively. Absorbance was measured on a Microtitre plate reader (Model 680, Bio-Rad, Hercules, CA) with a test wavelength of $550 \mathrm{~nm}$ and a reference wavelength of $655 \mathrm{~nm}$.

Immunofluorescence studies. DAOY and D283 cells were plated on sterile coverslips. After $24 \mathrm{~h}$, both $\mathrm{N}$ and $\mathrm{H}$ cells were washed and incubated in serum-free medium under hypoxic $\left(1.0 \% \mathrm{O}_{2}\right)$ and normoxic $\left(21 \% \mathrm{O}_{2}\right)$ conditions for $48 \mathrm{~h}$. 
Cultures were fixed in $4 \%$ formaldehyde, permeabilized with $0.1 \%$ Triton $\mathrm{X}-100$, and incubated with antibodies specific for N-cadherin, Vimentin, Zo-1, or SNAIL for $3 \mathrm{~h}$ followed by PE-conjugated secondary antibody. Preparations were mounted on slides using DAPI (Sigma) and examined using a fluorescent microscope connected to an Olympus camera.

Construction of siRNA-expressing plasmids. Plasmids were constructed as described previously (15). Two construct expressing shRNA for uPA (pU) and uPAR (pUR) gene were constructed using a pcDNA3 vector containing CMV promoter as described previously by our group (15). A pcDNA3scrambled vector with an imperfect sequence, which does not form a perfect hairpin structure, was used to develop the scrambled vector for use as a control (pSV).

Spheroid migration assay. Normal (N) and intermittent hypoxic-conditioned $(\mathrm{H})$ DAOY/D283 cells were transfected with pSV, pU or pUR as described previously (15). Cells $\left(2 \times 10^{4}\right)$ per well were seeded in ultralow attachment 96-well plates at $5 \% \mathrm{CO}_{2}$ and kept on a shaker at $160 \mathrm{rpm}$ for $48 \mathrm{~h}$ at $37^{\circ} \mathrm{C}$. Spheroids were transferred to 48 -well plates and kept under $21 \% \mathrm{O}_{2}$ conditions. The results were observed under a light microscope, and the migration distance was measured using Image Pro Discovery software (Fryer, Huntley, IL).

Matrigel invasion assay. Normal (N) and intermittent hypoxic-conditioned $(\mathrm{H}) \mathrm{DAOY} / \mathrm{D} 283$ cells were transfected with pSV, pU or pUR and kept under $21 \% \mathrm{O}_{2}$. Cells were trypsinized, and $0.5 \times 10^{5}$ cells were placed into Matrigelcoated transwell inserts (Fisher Scientific, Pittsburgh, PA) with an $8-\mu \mathrm{m}$ pore size. Cells were allowed to migrate through the Matrigel for $24 \mathrm{~h}$. Cells in the upper chamber were removed with a cotton swab. The cells that adhered on the outer surface of the transwell insert or had invaded through the Matrigel were fixed, stained with Hema-3 (Fisher Scientific), and counted under a light microscope as described previously (15).

In vitro angiogenesis assay. Microtubule network formation in endothelial cell induced by tumor-conditioned medium was determined as described previously (15). After $36 \mathrm{~h}$ of cell culture, medium was removed from $\mathrm{N}$ and $\mathrm{H}$ cells and $3 \mathrm{ml}$ of serum-free media was added and cultured for further $12 \mathrm{~h}$ under normoxic $\left(21 \% \mathrm{O}_{2}\right)$ conditions for $48 \mathrm{~h}$. This conditioned medium was added to human microvascular endothelial cells (HMEC-1) derived from dermis and provided by Dr Francisco J. Candal (Centers for Disease Control and Prevention, Atlanta, GA) that were seeded the previous day in 96-well plates and incubated for further $48 \mathrm{~h}$. The cells were stained with Hema-3 staining kit and formation of the microtubule networks was examined using a phase-contrast microscope equipped with a CC camera and evaluated using Discovery Image Pro software (Fryer).

Chick chorioallantoic membrane (CAM) assay. Fertilized white leghorn chicken eggs (Charles River Laboratories International, Inc. Wilmington, MA) were incubated at a humidity of $70 \%$ and $37^{\circ} \mathrm{C}$. On day 3 of incubation, a round hole was created into the shell after removal of $2-3 \mathrm{ml}$ of albumen allowing detachment of the embryo from the eggshell. Normal development was verified and dead embryos were excluded. The hole was sealed with tape and the eggs were returned to the incubator. On day 10 of develop-ment, small plastic rings made out of Thermanox ${ }^{\mathrm{TM}}$ discs were placed on the CAM and $25 \mu \mathrm{l}$ of conditioned medium collected from $\mathrm{N}$ and H DAOY cells were deposited into the rings after gentle laceration of the CAM surface. CAMs were examined daily, and after 17 days were photographed to check for angiogenesis with a digital camera (Olympus E330) attached to a stereomicroscope. Only CAMs still alive at day 17 were included in this analysis.

Flow cytometry. FACS analysis was performed as described earlier (16). Briefly, $\mathrm{N}$ and $\mathrm{H}$ cells were incubated under hypoxic $\left(1.0 \% \mathrm{O}_{2}\right)$ or normoxic $\left(21 \% \mathrm{O}_{2}\right)$ conditions for $48 \mathrm{~h}$ and collected. Cells were washed three times with ice-cold phosphate-buffered saline (PBS), stained with propidium iodide $(2 \mathrm{mg} / \mathrm{ml})$ in $4 \mathrm{mM} / 1$ sodium citrate containing $3 \%$ (w/v) Triton X-100 and $0.1 \mathrm{mg} / \mathrm{ml}$ RNase-A (Sigma). Cells were analyzed with the FACSCalibur System (BectonDickinson Bioscience, Rockville, MD). The percentages of cells undergoing different phases were assessed using Cell Quest software (Becton-Dickinson Bioscience).

In situ terminal-deoxytransferase-mediated dUTP nick-end labeling assay. The terminal-deoxytransferase-mediated dUTP nick-end labeling (TUNEL) assay was carried out to detect apoptotic cells after the above-described treatments. N and $\mathrm{H}$ cells were cultured on eight-well chamber slides at a density of $2 \times 10^{3}$ per well. After $48 \mathrm{~h}$ of transfection with $\mathrm{pU}$, pUR and pSV, cells were fixed after termination in $4 \%$ paraformaldehyde for $1 \mathrm{~h}$. TUNEL staining for the detection of apoptotic cells was carried out using the in situ cell death detection kit, fluorescein (Roche Molecular Biochemicals, Indianapolis, IN) as per the manufacturer's instructions. Briefly, the fixed cells were washed three times in PBS ( $5 \mathrm{~min} / \mathrm{wash}$ ), and finally incubated with $50 \mu 1$ terminal deoxynucleotidyl transferase end-labeling cocktail for $60 \mathrm{~min}$ at $37^{\circ} \mathrm{C}$ in dark and humid conditions. The reaction was then terminated, and the slides were washed three times in PBS and mounted with anti-fading gel mount (Biomed) mixed with DAPI. Slides were allowed to dry in the dark, observed under a fluorescent microscope (model Olympus IX71; Olympus Optical Co), and photographed. Results were compared with $\mathrm{pSV}$-transfected cells to analyze apoptosis.

Dorsal skin-fold chamber model. Athymic nude mice (nu/nu; 12 females, 6 each group, 4-6 weeks old) were bred and maintained within a specific pathogen-free environment. The implantation technique of the dorsal skin-fold chamber model has been described previously (17). Mice were anesthetized by intraperitoneal injection with ketamine $(50 \mathrm{mg} / \mathrm{kg}) /$ xylazine $(10 \mathrm{mg} / \mathrm{kg})$. A dorsal air sac was formed by injecting $10 \mathrm{ml}$ of air. Diffusion chambers (Fisher, Hampton, NH) were prepared by aligning $0.45-\mu \mathrm{m}$ millipore membranes (Fisher) on both sides of the rim of the $\mathrm{O}$ ring (Fisher) with sealant and sterilized by UV radiation overnight. $\mathrm{N}$ and $\mathrm{H}$ DAOY cells $\left(5 \times 10^{6}\right)$ were suspended in $100-200 \mu 1$ of sterile PBS and injected into the chamber through the opening of 
A
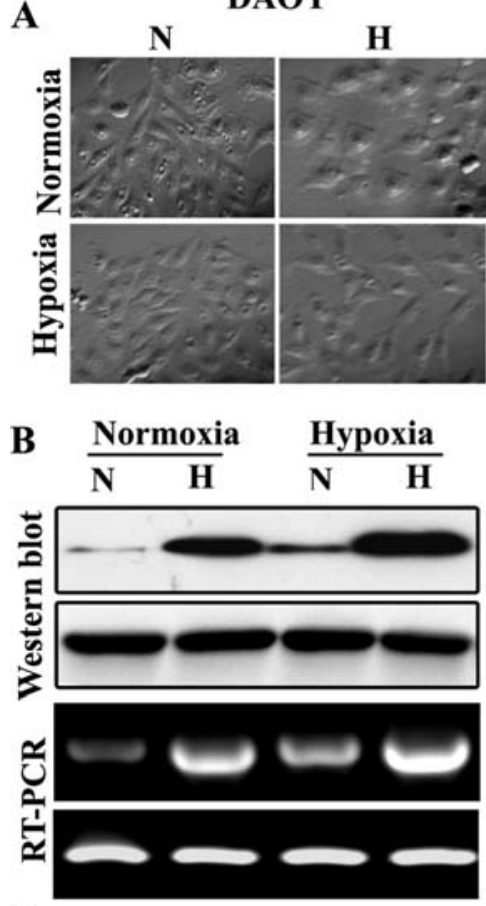

C

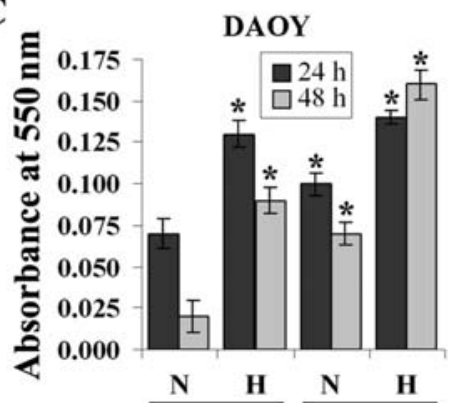

$\overline{\text { Normoxia }} \overline{\text { Hypoxia }}$
H

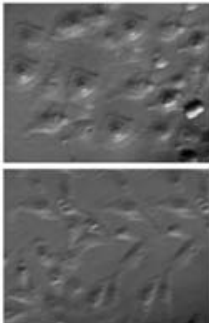

Hypoxia
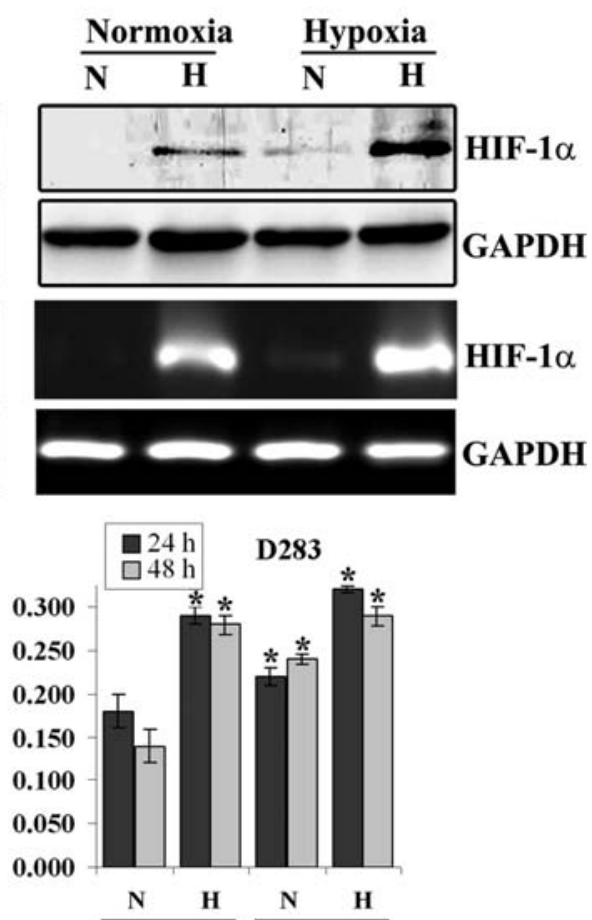

$\overline{\text { Normoxia }} \overline{\text { Hypoxia }}$

Figure 1. Intermittent hypoxia induces HIF-1 $\alpha$ at the protein and mRNA levels in medulloblastoma cell lines and promotes survival of tumor cells. Normal (N) and intermittent hypoxic-conditioned (H) DAOY/D283 cells were cultured for $48 \mathrm{~h}$ in $21 \% \mathrm{O}_{2}$ (normoxia) or $1 \% \mathrm{O}_{2}$ (hypoxia). (A) Cell images were captured by phase contrast microscopy. (B) Upper: Western blotting was carried out on total cell lysates of both $\mathrm{N}$ and $\mathrm{H}$ cells by monoclonal HIF-1 $\alpha$ antibody. Lower: reverse transcription was carried out on total RNA by using gene-specific HIF-1 $\alpha$ primers. (C) N and H cells were plated in 96-well microtiter plates and cultured for 24 and $48 \mathrm{~h}$ under both normoxic/hypoxic conditions. After 4-h incubation with MTT, DMSO was added to dissolve formazan crystals and absorbance values were read at $550 \mathrm{~nm}$. Columns: mean values of three independent experiments. Bars: SD. "p<0.05, significant difference from $\mathrm{N}$ cells cultured at normoxic conditions.

the $\mathrm{O}$ ring. The opening was sealed with a small amount of bone wax. A superficial incision was made horizontally along the edge of the dorsal air sac. With the help of forceps, the chambers were placed underneath the skin and carefully sutured in place. After 10 days, the animals were anesthetized, and the skin where diffusion chambers were implanted was photographed under visible light. All animal experiments were approved by our institutional ethics committee.

Densitometry. Densitometry was performed by using Image $\mathbf{J}$ Software (NIH) to quantify the band intensities obtained from Western blot and RT-PCR. Data represent values of three separate experiments.

Statistical analysis. All data are presented as means \pm SD of at least three independent experiments, each performed in triplicate. One way analysis of variance (ANOVA) combined with the Turkey post hoc test of means were used for multiple comparisons in cell culture experiments. Differences in the values were considered significant at $\mathrm{p}<0.05$.

\section{Results}

Intermittent hypoxia enhances HIF-1a at the transcriptional and translational levels and promotes tumor cell survival. To better model the tumor microenvironment, particularly at the hypoxic core, we cultured both normal and intermittent hypoxic-conditioned medulloblastoma cells in the hypoxic $\left(1.0 \% \mathrm{O}_{2}\right)$ and normoxic $\left(21 \% \mathrm{O}_{2}\right)$ conditions. Fig. 1A shows that intermittent hypoxic-conditioned $(\mathrm{H})$ DAOY and D283 cells lost its normal cell shape in comparison to respective normal $(\mathrm{N})$ cells.

To examine the expression level of hypoxia inducible factor $1 \alpha$, a hypoxia inducible gene, in these $\mathrm{N}$ and $\mathrm{H}$ cells we carried out Western blot analysis using HIF-1 $\alpha$ monoclonal 


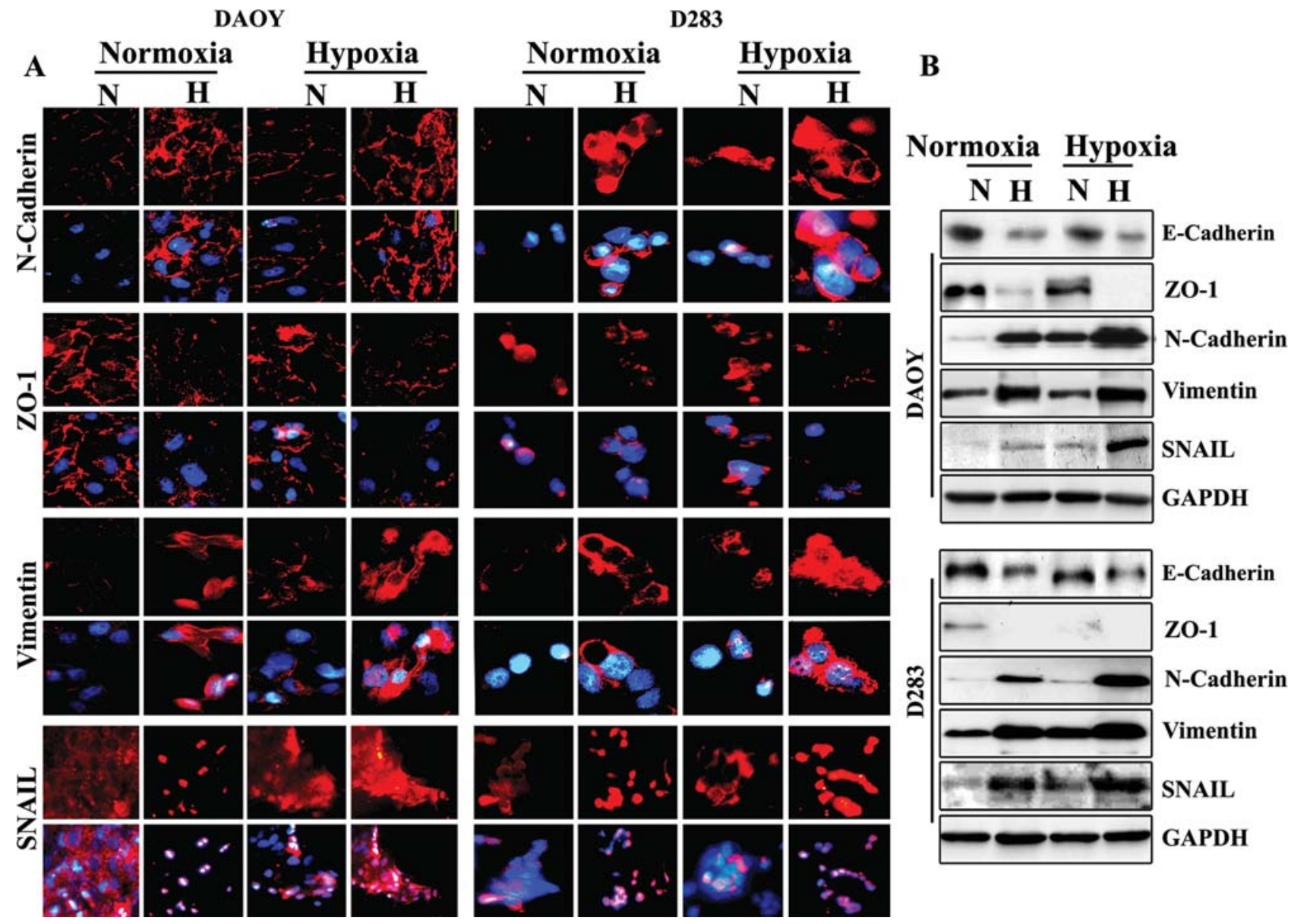

Figure 2. Intermittent hypoxia induces EMT in DAOY and D283 cells. Normal (N) and intermittent hypoxic-conditioned (H) cells were cultured for 48 h in $21 \% \mathrm{O}_{2}$ (normoxia) or $1 \% \mathrm{O}_{2}$ (hypoxia). (A) Cells were immunostained to detect N-cadherin, Vimentin, Zo-1 and SNAIL. (B) Cell lysates were subjected immunoblot analysis to detect N-cadherin, Vimentin, Zo-1 and SNAIL. GAPDH served as a loading control.

antibody. The expression of HIF-1 $\alpha$ was strongly induced in conditioned hypoxic DAOY and D283 cells, at the protein levels when compared with respective $\mathrm{N}$ cells. Exposure of $\mathrm{N}$ and $\mathrm{H}$ cells to hypoxic condition for $48 \mathrm{~h}$ further enhanced expression of HIF-1 $\alpha$. Next, we examined the mRNA transcript levels in these cells by RT-PCR. The mRNA levels also increased in $\mathrm{H}$ cells as compared with $\mathrm{N}$ and chronic hypoxic cells (Fig. 1B). These results clearly show that the expression of HIF-1 $\alpha$ was found to be higher in conditioned hypoxic cells in comparison to chronic hypoxic cells and $\mathrm{N}$ cells both at protein and RNA level.

To understand the effect of hypoxia on tumor cell growth, MTT assay was performed. N and H DAOY and D283 cells were cultured for 24 and $48 \mathrm{~h}$ under normoxic and hypoxic conditions as shown in Fig. 1C, the results demonstrated that intermittent hypoxic-conditioned DAOY and D283 cells exhibit increased viability after 24 (DAOY, 1.85-fold; D283, 1.6-fold; $\mathrm{p}<0.05$ ) and $48 \mathrm{~h}$ (DAOY, 4.5-fold; D283, 2-fold; $\mathrm{p}<0.05)$ as compared to normal cells. The survival of $\mathrm{H}$ cells was found to be better in comparison to chronic hypoxic cells after 24 (DAOY; 1.3-fold: D283; 1.3-fold) and 48 h (DAOY; 1.28-fold: D283; 1.2-fold).

Intermittent hypoxia induces EMT in DAOY/D283 cells. To further test whether the morphologic changes in hypoxic- conditioned cells represent EMT, we performed immunofluorescence studies to examine the epithelial cell marker Zo-1 and the mesenchymal cell markers $\mathrm{N}$-cadherin, Vimentin and SNAIL. As shown in Fig. 2A, H DAOY and H D283 cells show induced expression of $\mathrm{N}$-cadherin and Vimentin as compared to the $\mathrm{N}$ cells. In contrast, Zo-1, an epithelial marker, was lost from the cell surface in most of the $\mathrm{H}$ cells. This effect was found to be more effective when $\mathrm{N}$ and $\mathrm{H}$ cells were exposed to hypoxic conditions for further $48 \mathrm{~h}$. Under normoxic cell culture conditions $\left(21 \% \mathrm{O}_{2}\right)$, SNAIL was localized in the cytoplasm. In contrast, in $1.0 \% \mathrm{O}_{2}$, SNAIL translocated to the nucleus. The translocation of SNAIL was enhanced when both $\mathrm{N}$ and $\mathrm{H}$ cells were exposed to hypoxic conditions for further $48 \mathrm{~h}$ (Fig. 2A). Immunoblot analysis for N-cadherin, Vimentin, SNAIL, E-cadherin and Zo-1 in $\mathrm{H}$ DAOY/D283 cells showed increased levels of N-cadherin, Vimentin and SNAIL but decreased levels of E-cadherin and Zo-1 in $\mathrm{H}$ cells as compared to $\mathrm{N}$ and $\mathrm{N}$ cells exposed to hypoxic conditions for further $48 \mathrm{~h}$ (chronic hypoxic cells) (Fig. 2B).

Intermittent hypoxia promotes Matrigel invasion and cell migration in hypoxic-conditioned medulloblastoma cells. Since EMT is thought to promote cancer cell migration and invasion (18), we studied the effect of hypoxia on cell 
DAOY

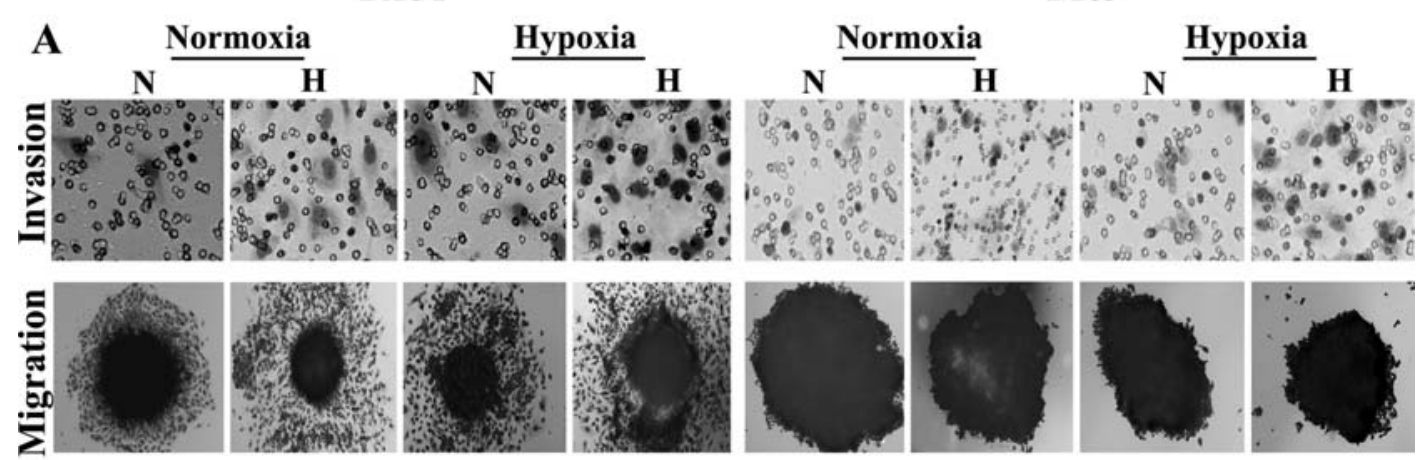

\section{B Migration}

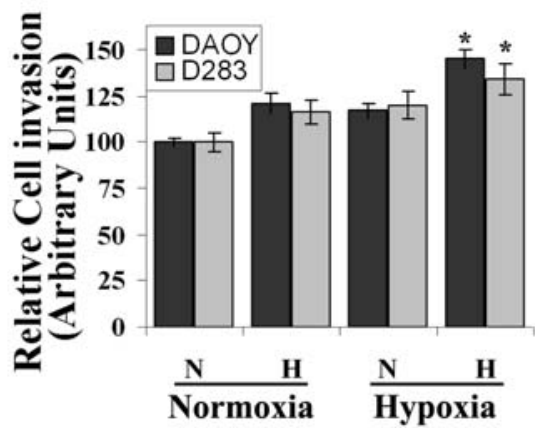

\section{Invasion}

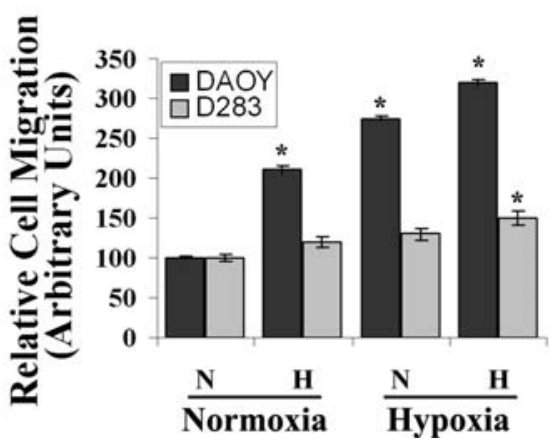

Figure 3. Intermittent hypoxia promotes cell migration and invasion in DAOY and D283 cells. Normal (N) and intermittent hypoxic-conditioned (H) cells of each cell line were cultured for $48 \mathrm{~h}$ in $21 \% \mathrm{O}_{2}$ (normoxia) or $1 \% \mathrm{O}_{2}$ (hypoxia). (A) Upper: cells were trypsinized and $0.4 \times 10^{5}$ cells were allowed to invade Matrigel-coated transwell inserts for $48 \mathrm{~h}$ at $37^{\circ} \mathrm{C}$. Then, the cells were fixed and stained with Hema-3. Cells that had invaded to the lower side of the membrane, and were photographed under a light microscope. Lower: similarly N and H DAOY and D283 cells $\left(2 \times 10^{4}\right)$ were plated into ultra low attachment 96-well plate and were kept on shaker at $160 \mathrm{rpm}$ for $48 \mathrm{~h}$ to form spheroids. Spheroids were cultured for $48 \mathrm{~h}$ under both normoxic/hypoxic conditions. The spheroids were then fixed and stained with Hema-3. Cellular migration from spheroids was assessed under a microscope. (B and C) Invaded cells were quantified by counting five fields in each condition. Distance migration of cells was expressed relative to the levels observed with the $\mathrm{N}$ cells cultured at normoxic conditions. Columns: mean of triplicate experiments, bars SD. ${ }^{*} \mathrm{p}<0.05$, significant difference from $\mathrm{N}$ cells cultured at normoxic conditions.

migration and invasion (Fig. 3). The results of Matrigel invasion assay showed induction of invasion in $\mathrm{H}$ cells as compared to N (DAOY: 2.1-fold; $\mathrm{p}<0.05$ cells; D283: 1.2fold). Exposure to hypoxia for another $48 \mathrm{~h}$, in these cells ( $\mathrm{N}$ and $\mathrm{H}$ ) further enhanced invasive capacity of the cells.

To study the effects of hypoxia on cell migration, we cultured spheroids of $\mathrm{N}$ and $\mathrm{H}$ cells in serum media in the incubator. We observed that DAOY hypoxic-conditioned cells showed an increase in migration as compared to $\mathrm{N}$ cells (1.2-fold) and chronic hypoxic cells (1.03-fold) Similarly D283 cells also showed similar pattern of migration however, the variation between $\mathrm{H}$ and $\mathrm{N}$ is not significant (Fig. 3C).

Intermittent hypoxia enhances angiogenesis in vitro and in vivo. We next determined the effect of hypoxia on angiogenesis. For this experiment, we performed in vitro capillarylike structure formation assays by using tumor-conditioned medium. Conditioned medium of H DAOY/D283 cells increased capillary-like structure formation in HMEC as compared to conditioned medium from $\mathrm{N}$ cells (Fig. 4; upper).

We next performed the ex vivo chick chorioallantoic membrane (CAM) assay using these cells. CAMs treated with tumor-conditioned medium from H DAOY/ D283 cells showed an increase in angiogenesis relative to CAMs treated with tumor-conditioned medium from $\mathrm{N}$ cells (Fig. 4; middle).

Further we performed a dorsal skin-fold chamber assay in nude female mice by putting $\mathrm{H}$ and $\mathrm{N}\left(1 \times 10^{6}\right)$ DAOY cells containing rings into dorsal skin. We found more neovascularization in $\mathrm{H}$ cells containing rings compared to $\mathrm{N}$ cells (Fig. 4, lower).

Intermittent hypoxia decreases apoptosis by enhancing expression of anti-apoptotic molecules and by downregulating proapoptotic molecules. We carried out cell cycle analysis to determine hypoxia affects on $\mathrm{N}$ and H DAOY/D283 cells. FACS analysis was carried using these cells that were cultured for $24 \mathrm{~h}$ under normoxic and hypoxic conditions. Quantification of $\mathrm{G}_{0}-\mathrm{G}_{1}$ was considered an apoptosis marker. The $\%$ of sub $\mathrm{G}_{0} / \mathrm{G}_{1}$ cell population was found to be reduced in H DAOY (5\%) and D283 (12\%) cells when compared with N cells (Fig. 5B). Based on the FACS results, we determined the effect of hypoxia on the levels of pro-apoptotic and anti-apoptotic molecules. SDS-PAGE analysis showed a decrease in pro-apoptotic proteins (e.g., Bax, Bad) and an increase in anti-apoptotic proteins (e.g., $\mathrm{Bcl} 2$ and $\mathrm{Bcl}-\mathrm{xL}$ ) in $\mathrm{H}$ cells as compared to $\mathrm{N}$ cells and chronic hypoxic cells (Fig. 5C). Further exposure of these $\mathrm{N}$ and $\mathrm{H}$ cells for $48 \mathrm{~h}$ in hypoxia enhanced its effect on pro- and anti-apoptotic proteins (Fig. 5C).

Intermittent hypoxia induces $u P A$ and $u P A R$ expression. $\mathrm{H}$ DAOY and D283 cells demonstrated substantially increased uPA (DAOY; 2-fold: D283; 6-fold; p<0.01) and uPAR (DAOY; 6-fold: D283; 4-fold; $\mathrm{p}<0.01$ ) expression in 

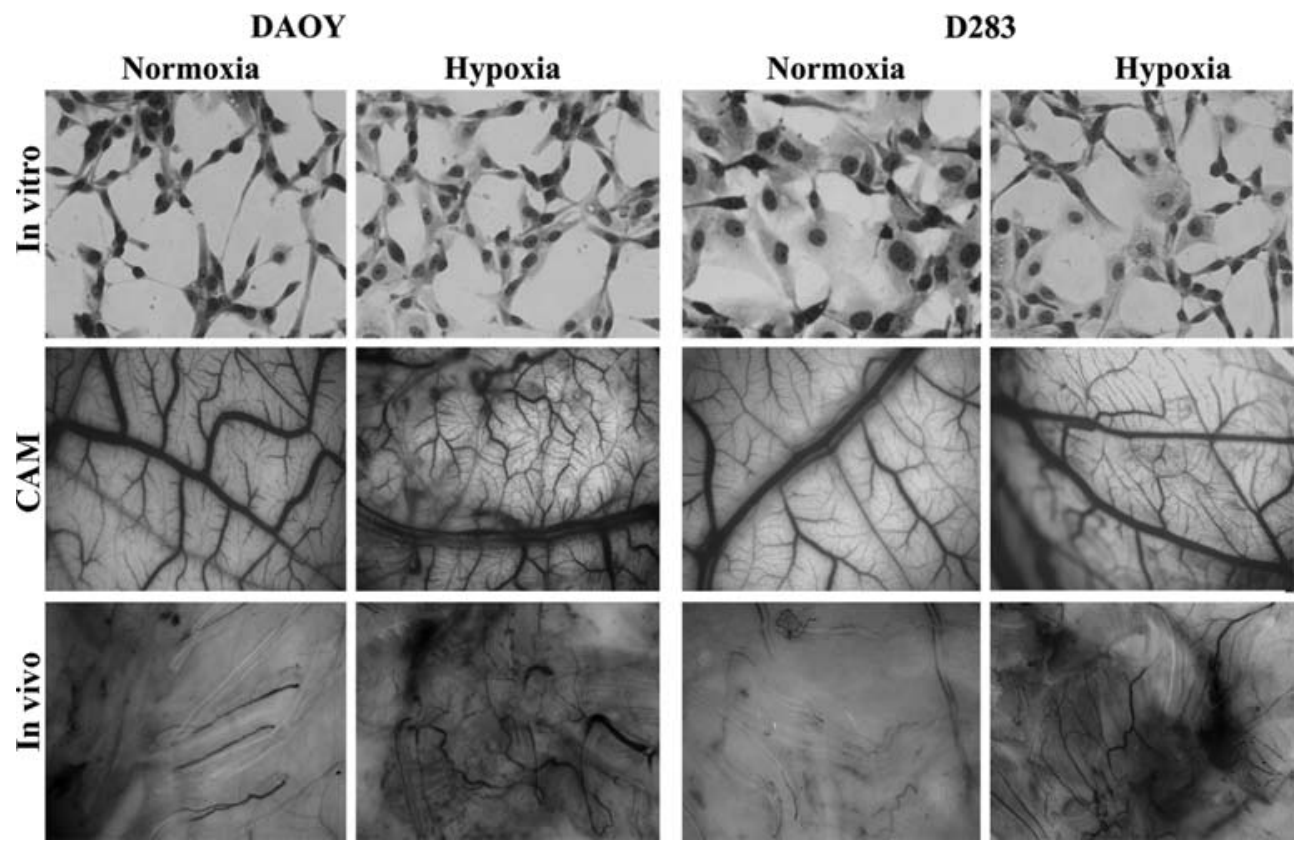

Figure 4. Hypoxia enhances angiogenesis in vitro and in vivo in DAOY and D283 cells. Upper: human microvascular endothelial cells $\left(2 \times 10^{6}\right)$ were seeded in 96-well plates and cultured with conditioned medium collected from $\mathrm{N}$ and $\mathrm{H}$ cells. The HMEC cells were kept for $48 \mathrm{~h}$ at $21 \% \mathrm{O}_{2}$, washed, fixed, stained with Hema-3, and photographed. Middle: tumor-conditioned media from normal (N) and intermittent hypoxic-conditioned (H) DAOY and D283 cells were tested for angiogenic activity using the chick chorioallantoic membrane (CAM) assay. Lower: athymic nude mice ( $\mathrm{n}=12$, nu/nu, 6 each group, female, 18-25 g) were bred and maintained within a specific pathogen-free environment. $\mathrm{N}$ and $\mathrm{H}$ cells were implanted within a dorsal skin-fold chamber, which contains two layers of the membrane on both sides of a ring. This model is characterized by both solid and diffuse infiltrative growth patterns.

\section{DAOY}

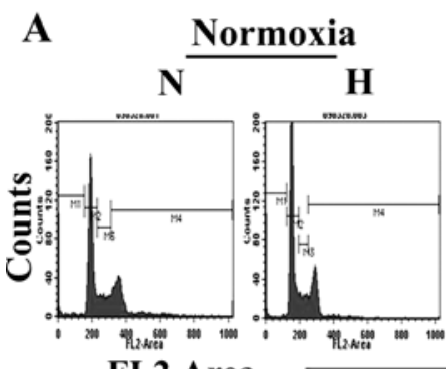

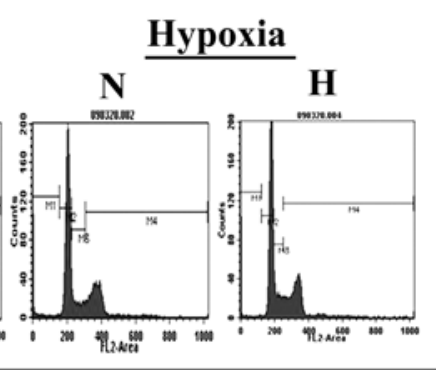

D283
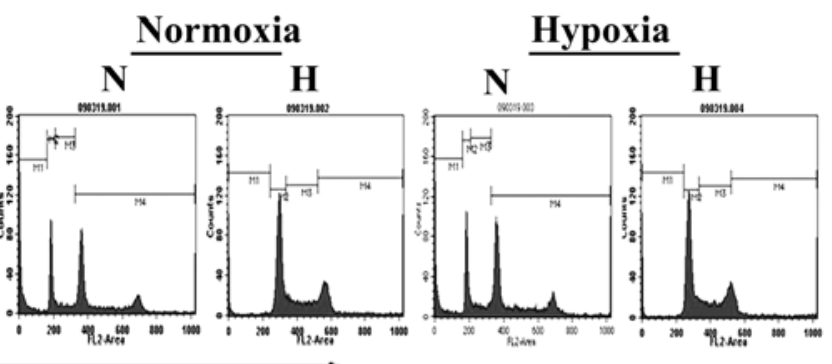

\section{B}

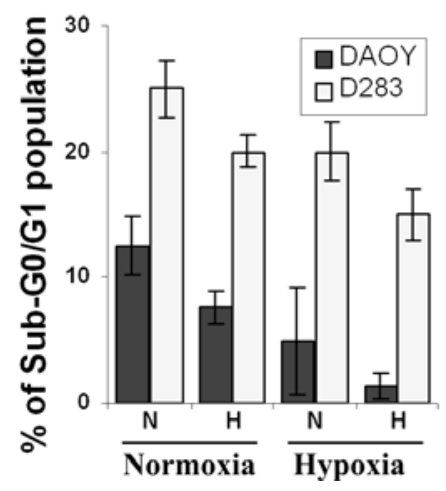

C Normoxia Hypoxia Normoxia Hypoxia

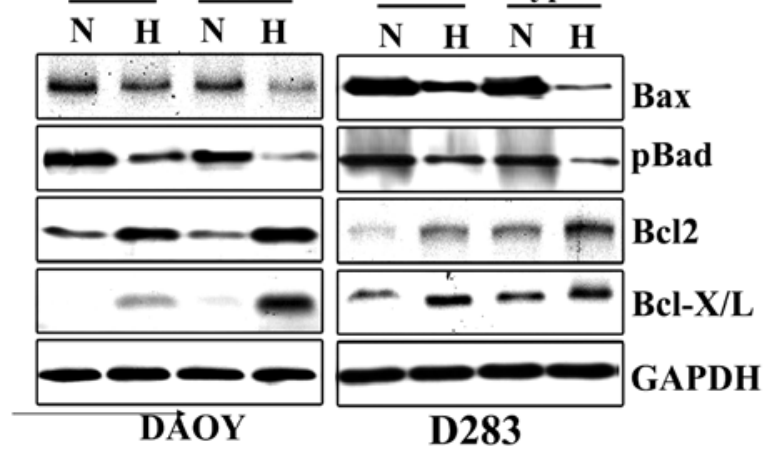

Figure 5. Intermittent hypoxia downregulates pro-apoptotic molecules and upregulates anti-apoptotic proteins in DAOY and D283 cells. Normal (N) and intermittent hypoxic-conditioned $(\mathrm{H})$ cells of each cell line were cultured for $48 \mathrm{~h}$ in $21 \% \mathrm{O}_{2}$ (normoxia) or $1 \% \mathrm{O}_{2}$ (hypoxia). Cells were collected and washed three times with ice-cold PBS, stained with propidium iodide ( $2 \mathrm{mg} / \mathrm{ml})$ in $4 \mathrm{mM} / \mathrm{l}$ sodium citrate containing $3 \%$ (w/v) Triton X-100 and Rnase-A (0.1 mg/ml), and analyzed with the FACSCalibur System. (B) The percentages of cells under sub $\mathrm{G}_{0}-\mathrm{G}_{1}$ phases were assessed using Cell Quest Software. Columns: mean of triplicate experiments, bars SD. (C) Western blotting was done on total cell lysates of cells using antibodies specific for pro-apoptotic (p-Bad and Bax) and anti-apoptotic (Bcl2 and $\mathrm{Bcl}-\mathrm{xL})$ proteins. 


\section{A}

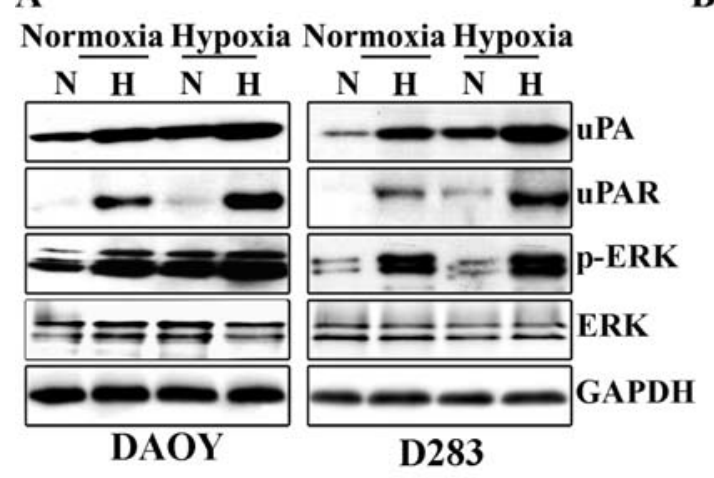

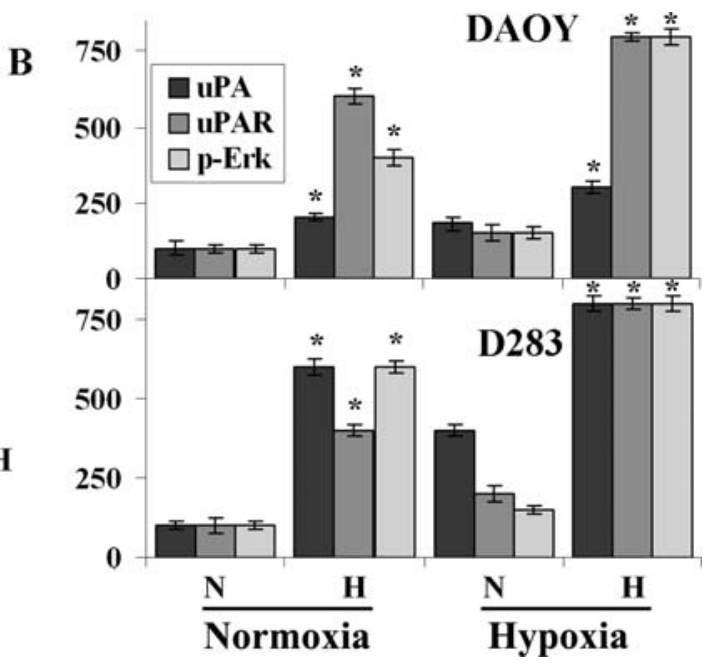

Figure 6. Intermittent hypoxia increases uPA and uPAR levels and activates cell signaling factors downstream of uPAR. Normal (N) and intermittent hypoxicconditioned (H) DAOY/D283 cells were cultured for $48 \mathrm{~h}$ in $21 \% \mathrm{O}_{2}$ (normoxia) or $1 \% \mathrm{O}_{2}$ (hypoxia). (A). Cell lysates were subjected to Western blotting for uPA, uPAR p-ERK and ERK. The original extracts were studied by immunoblot analysis to determine p-ERK and total ERK levels. GAPDH served as a loading control. (B) Western blot results were quantified by using Image J Software. The results of three separate experiments were averaged to determine the percentage of increase in activated uPA, uPAR and p-ERK in hypoxic conditions in both DAOY and D283 cells. Columns: mean of triplicate experiments; bars: SD. ${ }^{*} \mathrm{p}<0.01$, significant difference from $\mathrm{N}$ cells transfected with $\mathrm{pSV}$.

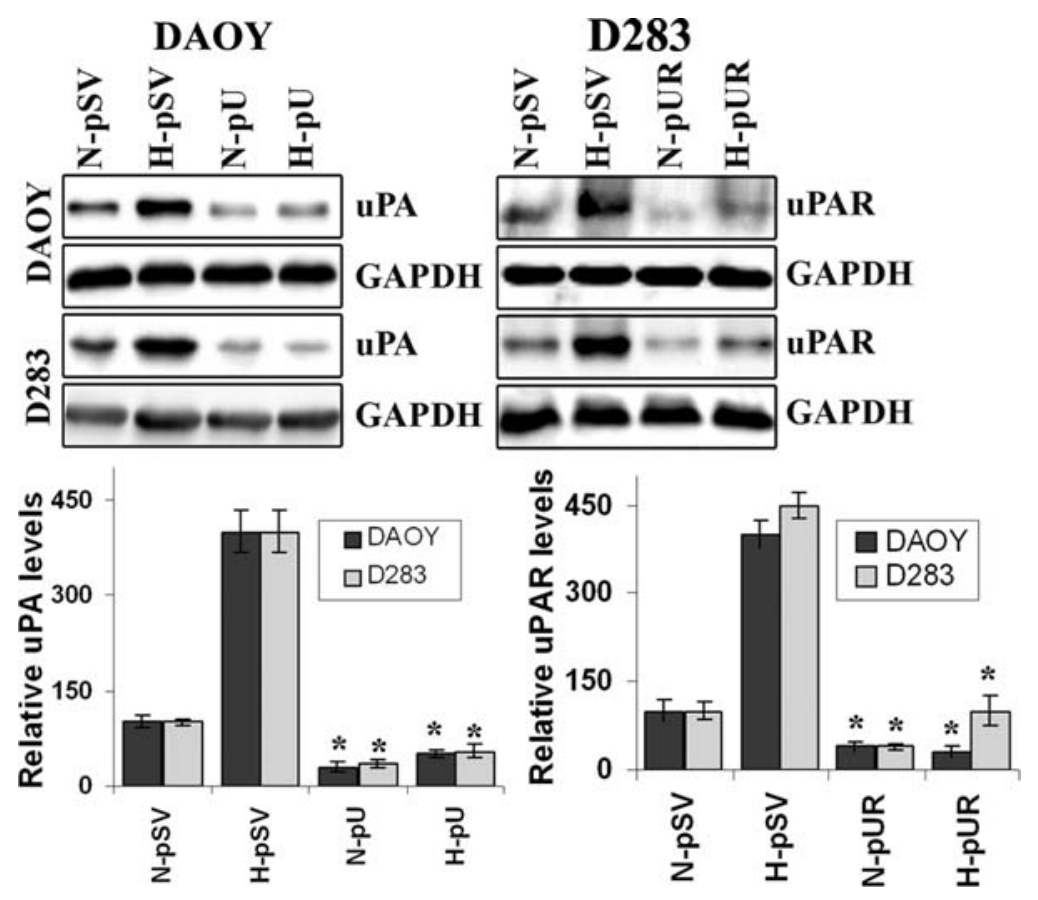

Figure 7. Downregulation of uPA and uPAR by p-U and p-UR, respectively. (A) Normal (N) and intermittent hypoxic-conditioned (H) DAOY/D283 cells $\left(1 \times 10^{6}\right)$ were transfected with p-U and p-UR and cultured under normoxic and hypoxic conditions for $48 \mathrm{~h}$. Cell lysates were subjected to SDS-PAGE, and immunoblot analysis was carried out to detect uPA and uPAR level. (B) Western blot results were quantified by using Image J Software. Columns: mean of triplicate experiments, bars SD. ${ }^{\mathrm{p}}<0.05$, significant difference from respective cells transfected with $\mathrm{pSV}$.

comparison to normoxic cells, as determined by immunoblot analysis (Fig. 6A and B). We hypothesized that activation of uPAR-dependent cell signaling may be responsible for the molecular and morphological changes observed in hypoxicconditioned medulloblastoma cells. To test this hypothesis, we examined the basal level of activation of ERK in cells maintained in $21 \% \mathrm{O}_{2}$ and $1 \% \mathrm{O}_{2}$. Fig. 6A and $\mathrm{B}$ shows increased levels of p-ERK levels in hypoxic conditioned cells in comparison to normoxic (DAOY; 4-fold: D283; 6-fold; $\mathrm{p}<0.01$ ) and chronic hypoxic cells (DAOY; 2.7-fold: D283; 4-fold; $\mathrm{p}<0.01)$. Quantitative analysis demonstrated p-ERK levels in $1.0 \% \mathrm{O}_{2}$ was statistically significant $(\mathrm{p}<0.05)$ in both cell lines.

Si-RNA-mediated downregulation of $U P A$ and $u P A R$ by $p U$ and $p U R$. As we found more prominent effect of intermittent 

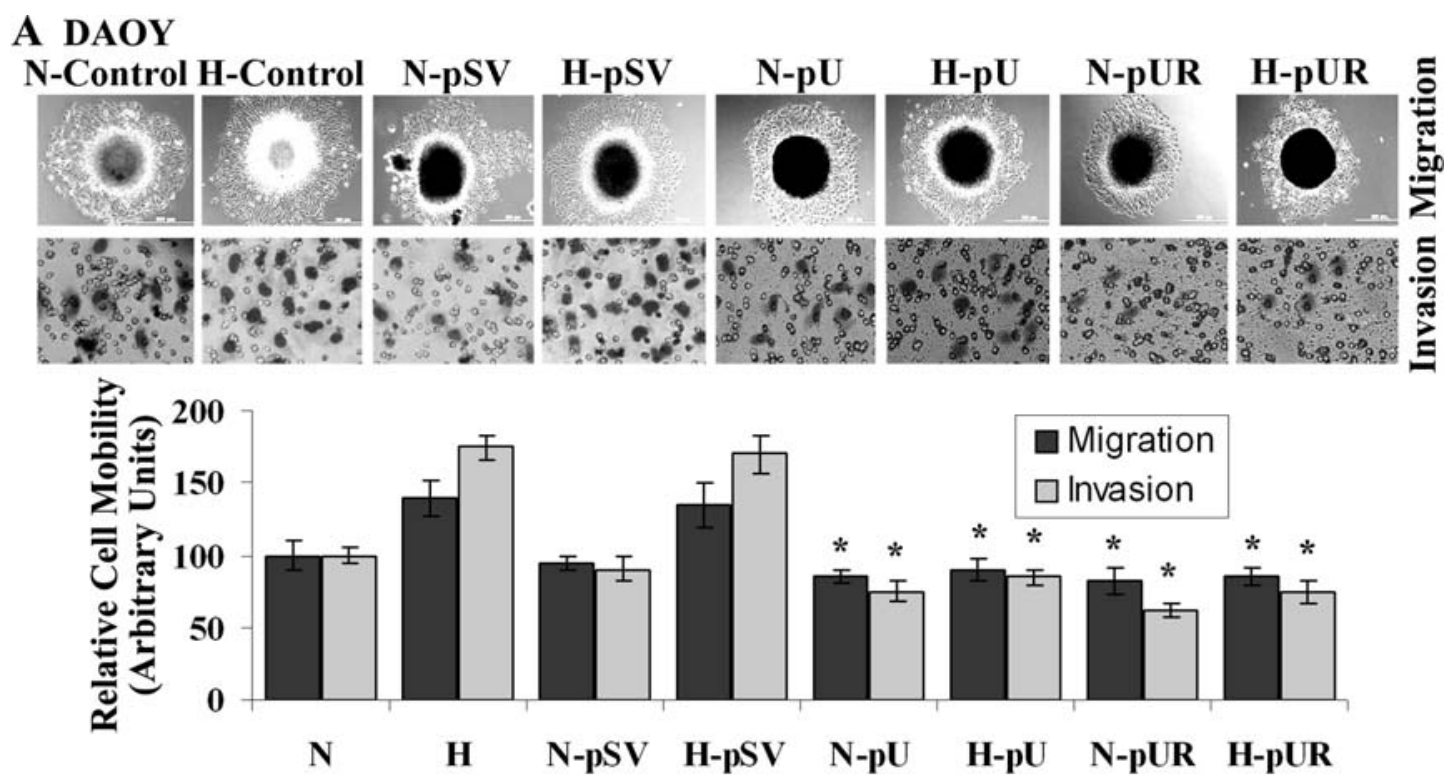

B D283


Figure 8. Downregulation of uPA and uPAR decreases hypoxia-induced cell migration and invasion in DAOY and invasion in D283 cells. Normal (N) and intermittent hypoxic-conditioned (H) DAOY/D283 cells were transfected with scrambled vector (pSV), pupa siRNA (pU) and puPAR siRNA (pUR) for 48 h. (A) Upper: DAOY cells were cultured to form spheroids and kept for $48 \mathrm{~h}$ under normoxic conditions; spheroids were then fixed and stained with Hema-3. Cellular migration from spheroids was assessed under microscope. Lower: transfected DAOY cells of both normoxic and hypoxic conditions were allowed to invade Matrigel-coated transwell inserts for $48 \mathrm{~h}$ at $37^{\circ} \mathrm{C}$ after which they were fixed and stained with Hema-3. Cells that had migrated to the lower side of the membrane were photographed under a light microscope. Cellular migration and invasion in $\mathrm{H}$ cells after transfection with pU and pUR are expressed relative to the levels observed with $\mathrm{N}$ controls. Columns: mean of triplicate experiments, bars SD. ${ }^{*} \mathrm{p}<0.05$, significant difference from respective cells transfected with pSV. (B) Invasion was performed for D283 cells as above. Percentages of invading cells were quantified by counting five fields in each condition. (C) Cell lysates from transfected cells were analyzed by Western blotting to detect HIF-1 $\alpha$. Columns: mean of triplicate experiments, bars SD. ${ }^{*}$ p $<0.05$, significant difference from respective cells transfected with $\mathrm{pSV}$.

hypoxia on uPA/uPAR expression when compared with Normoxia and chronic hypoxia, therefore we continued our further si-RNA-based study on intermittent hypoxicconditioned cells. To further test the role of uPA/uPAR, we silenced these genes by si-RNA-mediated uPA and UPAR constructs. We found a significant decrease in UPA and UPAR, when N (DAOY: $70 \%$ decrease in UPA, $60 \%$ decrease in UPAR; D283: 65\% decrease in uPA, 60\% decrease in uPAR; $\mathrm{p}<0.05)$ ) and $\mathrm{H}$ (DAOY: $87 \%$ decrease in uPA, $90 \%$ decrease in uPAR; D283: 87\% decrease in uPA, 77\% decrease in uPAR; $\mathrm{p}<0.05) \mathrm{DAOY}$ and D283 cell lines were treated with $\mathrm{pU}$ and $\mathrm{pUR}$ single si-RNA-mediated construct, respectively (Fig. 7).
siRNA against UPAR/uPA downregulates hypoxia-induced cell migration and invasion. To test whether UPAR is responsible for the increase in cell migration observed in hypoxia, we applied a gene silencing approach. For this, we transfected DAOY and D283 cells with plasmid vectors carrying siRNA against uPA and UPAR. H DAOY cells showed a significant decrease in cell migration in comparison to $\mathrm{N}$ cells when transfected with the uPAR $(\mathrm{H}, 40 \% ; \mathrm{N}, 18 \%$; $\mathrm{p}<0.05)$ siRNA plasmid; however, the decrease in migration was less pronounced with uPA $(\mathrm{H}, 35 \% ; \mathrm{N}, 15 \%$; $<<0.05)$ gene silencing (Fig. 8A). We did not study migration in D283 cells as these cells did not show any significant migration under hypoxic conditions. 

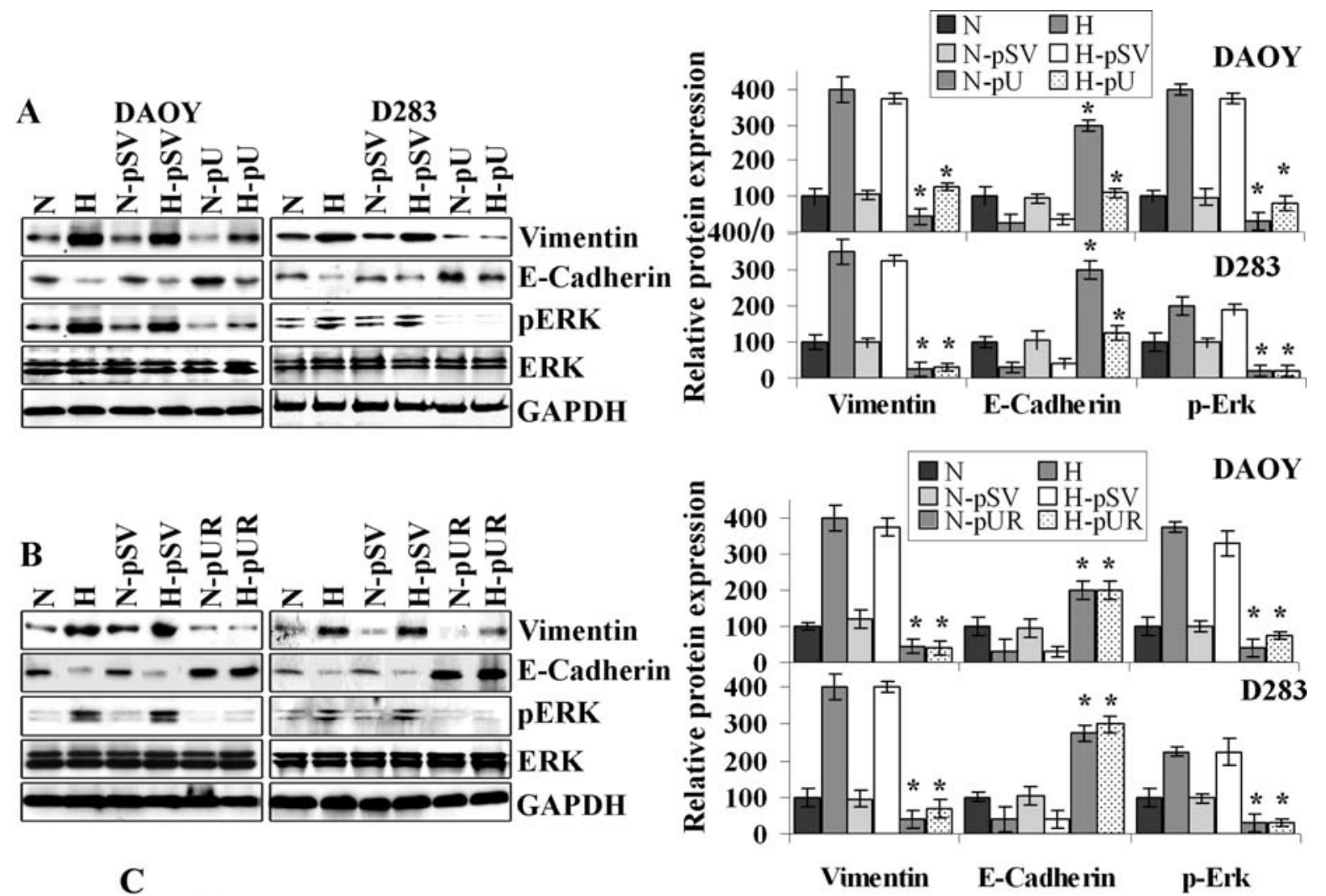

C

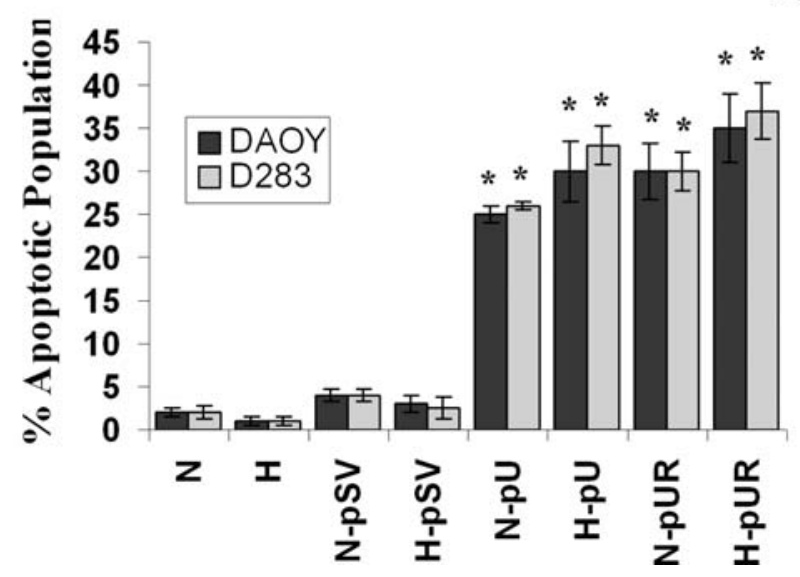

Figure 9. Downregulation of uPA and uPAR leads to reduction in hypoxia-induced EMT in DAOY and D283 cells. (A and B) Normal (N) and intermittent hypoxic-conditioned $(\mathrm{H})$ DAOY and D283 cells $\left(1 \times 10^{5}\right)$ were transfected with pupa siRNA (pU) and puPAR siRNA (pUR) under normoxic conditions. Cell lysates were subjected to SDS-PAGE, and immunoblot analysis was carried out to detect Vimentin, E-cadherin, p-ERK and ERK. GAPDH served as a loading control. The band intensities were quantified using Image J Software. Columns: mean of triplicate experiments; bars: SD. "p<0.05, significant difference from respective cells transfected with pSV. (C) Cells were evaluated with the TUNEL assay after transfection with pU and pUR as per manufacturer's instructions and photographed under fluorescent microscopy. Apoptosis was measured by counting the percentage of cells that showed DNA staining in five different fields in each group. Columns: mean of triplicate experiments; bars: SD. *p<0.01, significant difference from $\mathrm{N}$ cells transfected with pSV.

In Matrigel invasion experiments performed under normoxic conditions, uPA/uPAR gene silencing in hypoxicconditioned DAOY and D283 cells resulted in a significant decrease in invasion as compared to $\mathrm{N}$ cells (DAOY: $\mathrm{H}$, 51\%; N, 25\% with pU; H, 57\%; N, 38\% with pUR; D283:H, $60 \%$; N, 40\% with pU; H, 75\%; N, 45\% with pUR; $\mathrm{p}<0.05$ ). We found a reduced expression of HIF- $1 \alpha$ in pU/pURtransfected cells as compared to the untransfected $\mathrm{N}$ and $\mathrm{H}$ cells (Fig. 8C).

UPA/uPAR correlation with EMT and apoptosis. To further test the role of uPA and uPAR on EMT in H DAOY/D283 cells, we examined the effects of UPA and UPAR gene silencing on EMT markers using Western blot analysis. Upon silencing of UPA and UPAR genes by siRNA, H DAOY cells demonstrated a significant decrease in mesenchymal molecules, including Vimentin (uPA; 68\%: uPAR; 90\%; $<<0.05$ ), with a concomitant increase in epithelial markers, such as E-cadherin (uPA; 4.4-fold: uPAR; 6.6-fold; $\mathrm{p}<0.05$ ) as compared to N (Vimentin: uPA, 55\% uPAR, 55\%; E-cadherin uPA, 3-fold; uPAR, 2-fold $\mathrm{p}<0.05$ ) cells (Fig. 9A). In contrast to DAOY cells, H D283 cells show dramatically increased E-cadherin expression (7.5-fold) upon uPAR gene silencing as compared with uPA (4.1-fold) gene silencing (Fig. 9B). 
We have previously shown that uPA/uPAR knockdown induces apoptosis in gliomas cells (15). We want to examine the effect of uPA/uPAR silencing on the apoptosis of these $\mathrm{N}$ and $\mathrm{H}$ cells. The effect of constructs was found to be more effective in case of $\mathrm{H}$ cells. However, both constructs enhance apoptosis in hypoxic cells but this effect was relatively more effective with pUR (DAOY; H, 34\%, N, 28\%: D283; H, 36\%, N, 28\%) as compared to pU (DAOY: H, 29\%: N, 23\%; D283; H, 32\%, N, 24\%) in both cell lines (Fig. 9C).

\section{Discussion}

Cellular adaptations observed in local hypoxia include changes in cell signaling and gene expression, which promote not only cell survival, but also cell migration, invasion, metastasis and resistance to chemotherapy (19). In tumors, hypoxia typically develops when cancer cells are separated from blood vessels by $>180 \mu \mathrm{m}$. However, some hypoxic cancer cells activate pro-survival cell signaling pathways, which coincidentally also promote cell migration and invasion (20). Many but not all of the changes in cellular transcription observed in hypoxia reflect increased levels of HIF-1 $\alpha$, which translocates to the nucleus and, after heterodimerization with HIF-1ß, binds to hypoxia-response elements in gene promoters $(21)$. In the present study we also observed enhanced expression of HIF-1 $\alpha$ in intermittent hypoxicconditioned DAOY/D283 cells when compared with either normal or chronic hypoxic cells. Increased levels of HIF-1 $\alpha$ are associated with a poor prognosis in human malignancies, including cancers of the colon, breast, kidney and prostate $(22,23)$. Considering these facts of hypoxia on cancer cell physiology we tried to identify individual gene products that may be targeted to counteract the adverse effects of hypoxia in cancer.

Cancer cell EMT is thought to promote metastasis, but effect of hypoxia on EMT is still debated $(7,24)$. In the present study, we showed that intermittent hypoxia has more pronounced effects than chronic hypoxia on EMT, invasion, migration and survival of hypoxic-conditioned medulloblastoma cells. We also showed that molecules associated with EMT such as Vimentin, N-cadherin and SNAIL are activated in intermittent hypoxia; however, the epithelial marker (E-cadherin, Zo-1) is being downregulated in the same conditions. These results are consistent with the studies done previously $(13,24-29)$.

Hypoxia induces expression of uPAR, and this event is associated with increased cell migration and invasion in breast cancer cell lines. Here we found pronounced effect of hypoxia on UPAR expression; however this effect was more prominent in hypoxic-conditioned cells when compared with chronic hypoxic cells. Therefore, we continued our further siRNA-based study in intermittent hypoxic-conditioned cells only. We also found activation of p-ERK in hypoxia which provides one mechanism by which UPAR may regulate SNAIL and thus, promote EMT. UPAR overexpression has been shown to be associated with EMT (8). uPAR may not independently induce EMT in many cancer cells. Instead, other receptors, such as receptor tyrosine kinases and integrins, may work in concert with UPAR by activating an overlapping continuum of cell signaling pathways that control E-cadherin activity and EMT (8). It is quite possible that in some cancer cells, uPAR and other factors that support EMT may be induced simultaneously by hypoxia, downstream of HIF- $1 \alpha$. However, the prognosis of cancer may be adversely affected by EMT (30). Understanding the relationship between uPAR and other factors induced by HIF-1 $\alpha$ that may support EMT is a goal for future studies. Therefore, we silenced both uPA and UPAR by plasmid vector-mediated delivery of uPA ( $p U$ ) and uPAR (pUR) siRNA. We showed that silencing of uPA and UPAR reduces the effect of hypoxia on cellular migration, invasion and EMT, however effect of uPAR was found to be more pronounced over uPA. This silencing also enhance apoptosis in both normal and intermittent hypoxic-conditioned cells, however, this effect was found to be relatively more effective in case of intermittent hypoxic-conditioned cells when compared with normal cells.

The results presented here clearly suggest the more prominent effect of intermittent hypoxia on migration, invasion and EMT when compared to either normoxia or chronic hypoxia. We also showed high levels of uPA/uPAR in intermittent hypoxic-conditioned cells which may be responsible for hypoxia-induced EMT. Upon silencing of these genes by $\mathrm{pU}$ and $\mathrm{pUR}$, we observed a reduction in hypoxia-induced cellular migration, invasion and EMT. The effect of pUR was found to be more effective over pU. Taken together, the results of the present study provide valuable evidence of the anti-tumor efficacy of plasmid vector-mediated delivery of uPA/uPAR siRNA in intermittent hypoxicconditioned medulloblastoma cells to target intermittent hypoxia-induced cell invasion, migration, EMT and apoptosis. This strategy can be used to achieve better therapeutic outcomes in the treatment of malignant medulloblastoma.

\section{Acknowledgements}

We thank Shellee Abraham for manuscript preparation, and Diana Meister and Sushma Jasti for manuscript review. This research was supported by the Illinois Neurological Institute Peoria, IL (to D.H.D.).

\section{References}

1. Giangaspero $\mathrm{H}$, Bigner $\mathrm{SH}$, Kleihues $\mathrm{P}$, Pietsch $\mathrm{T}$ and Trojanowski JQ: Medulloblastoma. In: Tumours of the Nervous System (World Health Organisation Classification of Tumours). Kleihues P and Cavenee WK (eds). IARC Press, Lyon, pp129-137, 2000.

2. Gilbertson RJ: Medulloblastoma: signalling a change in treatment. Lancet Oncol 5: 209-218, 2004.

3. Akakura N, Kobayashi M, Horiuchi I, Suzuki A, Wang J, Chen J, Niizeki H, Kawamura K, Hosokawa M and Asaka M: Constitutive expression of hypoxia-inducible factor-1alpha renders pancreatic cancer cells resistant to apoptosis induced by hypoxia and nutrient deprivation. Cancer Res 61: 6548-6554, 2001.

4. Martinive P, Defresne F, Bouzin C, Saliez J, Lair F, Gregoire V, Michiels C, Dessy C and Feron O: Preconditioning of the tumor vasculature and tumor cells by intermittent hypoxia: implications for anticancer therapies. Cancer Res 66: 11736-11744, 2006.

5. Moeller BJ and Dewhirst MW: Raising the bar: how HIF-1 helps determine tumor radiosensitivity. Cell Cycle 3: 1107-1110, 2004.

6. Harrison L and Blackwell K: Hypoxia and anemia: factors in decreased sensitivity to radiation therapy and chemotherapy? Oncologist 9 (Supp. 5): S31-S40, 2004. 
7. Thompson EW, Newgreen DF and Tarin D: Carcinoma invasion and metastasis: a role for epithelial-mesenchymal transition? Cancer Res 65: 5991-5995, 2005.

8. Lester RD, Jo M, Montel V, Takimoto S and Gonias SL: uPAR induces epithelial-mesenchymal transition in hypoxic breast cancer cells. J Cell Biol 178: 425-436, 2007.

9. Graham CH, Forsdike J, Fitzgerald CJ and Donald-Goodfellow S: Hypoxia-mediated stimulation of carcinoma cell invasiveness via upregulation of urokinase receptor expression. Int J Cancer 80: 617-623, 1999

10. Rofstad EK, Rasmussen H, Galappathi K, Mathiesen B, Nilsen K and Graff BA: Hypoxia promotes lymph node metastasis in human melanoma xenografts by up-regulating the urokinasetype plasminogen activator receptor. Cancer Res 62: 1847-1853, 2002.

11. Lester RD, Jo M, Campana WM and Gonias SL: Erythropoietin promotes MCF-7 breast cancer cell migration by an ERK mitogen-activated protein kinase-dependent pathway and is primarily responsible for the increase in migration observed in hypoxia. J Biol Chem 280: 39273-39277, 2005.

12. Pennacchietti S, Michieli P, Galluzzo M, Mazzone M, Giordano S and Comoglio PM: Hypoxia promotes invasive growth by transcriptional activation of the met protooncogene. Cancer Cell 3: 347-361, 2003.

13. Krishnamachary B, Berg-Dixon S, Kelly B, Agani F, Feldser D, Ferreira G, Iyer N, LaRusch J, Pak B, Taghavi P and Semenza GL: Regulation of colon carcinoma cell invasion by hypoxiainducible factor 1. Cancer Res 63: 1138-1143, 2003.

14. Zhang F, Tom CC, Kugler MC, Ching TT, Kreidberg JA, Wei Y and Chapman HA: Distinct ligand binding sites in integrin alpha3beta1 regulate matrix adhesion and cell-cell contact. J Cell Biol 163: 177-188, 2003.

15. Gondi CS, Lakka SS, Yanamandra N, Siddique K, Dinh DH, Olivero WC, Gujrati $\mathrm{M}$ and Rao JS: Expression of antisense uPAR and antisense uPA from a bicistronic adenoviral construct inhibits glioma cell invasion, tumor growth, and angiogenesis. Oncogene 22: 5967-5975, 2003.

16. Rao JS, Bhoopathi P, Chetty C, Gujrati M and Lakka SS: Matrix metalloproteinase-9 short interfering RNA induced senescence resulting in inhibition of medulloblastoma growth via p16INK4 and mitogen-activated protein kinase pathway. Cancer Res 67: 4956-4964, 2007.

17. Graham, FL and Prevec L: Manipulation of adenovirus vectors. In: Methods in Molecular Biology. Murray E J (ed). The Humana Press, Clifton, NJ, pp109-127, 1991.
18. Grunert S, Jechlinger $\mathrm{M}$ and Beug $\mathrm{H}$ : Diverse cellular and molecular mechanisms contribute to epithelial plasticity and metastasis. Nat Rev Mol Cell Biol 4: 657-665, 2003.

19. Zhou J, Schmid T, Schnitzer S and Brune B: Tumor hypoxia and cancer progression. Cancer Lett 237: 10-21, 2006.

20. Harris AL: Hypoxia-a key regulatory factor in tumour growth. Nat Rev Cancer 2: 38-47, 2002.

21. Wang GL, Jiang BH, Rue EA and Semenza GL: Hypoxiainducible factor 1 is a basic-helix-loop-helix-PAS heterodimer regulated by cellular $\mathrm{O}_{2}$ tension. Proc Natl Acad Sci USA 92: 5510-5514, 1995.

22. Talks KL, Turley H, Gatter KC, Maxwell PH, Pugh CW, Ratcliffe PJ and Harris AL: The expression and distribution of the hypoxia-inducible factors HIF-1alpha and HIF-2alpha in normal human tissues, cancers, and tumor-associated macrophages. Am J Pathol 157: 411-421, 2000.

23. Zhong H, De Marzo AM, Laughner E, Lim M, Hilton DA, Zagzag D, Buechler P, Isaacs WB, Semenza GL and Simons JW: Overexpression of hypoxia-inducible factor 1alpha in common human cancers and their metastases. Cancer Res 59: 5830-5835, 1999.

24. Tarin D, Thompson EW and Newgreen DF: The fallacy of epithelial mesenchymal transition in neoplasia. Cancer Res 65: 5996-6000, 2005.

25. Imai T, Horiuchi A, Wang C, Oka K, Ohira S, Nikaido T and Konishi I: Hypoxia attenuates the expression of E-cadherin via up-regulation of SNAIL in ovarian carcinoma cells. Am J Pathol 163: 1437-1447, 2003.

26. Blasi F and Carmeliet P: uPAR: a versatile signalling orchestrator. Nat Rev Mol Cell Biol 3: 932-943, 2002.

27. Jo M, Thomas KS, Marozkina N, Amin TJ, Silva CM, Parsons SJ and Gonias SL: Dynamic assembly of the urokinase-type plasminogen activator signaling receptor complex determines the mitogenic activity of urokinase-type plasminogen activator. J Biol Chem 280: 17449-17457, 2005.

28. Jo M, Thomas KS, O'Donnell DM and Gonias SL: Epidermal growth factor receptor-dependent and -independent cellsignaling pathways originating from the urokinase receptor. J Biol Chem 278: 1642-1646, 2003.

29. Ossowski L and Aguirre-Ghiso JA: Urokinase receptor and integrin partnership: coordination of signaling for cell adhesion, migration and growth. Curr Opin Cell Biol 12: 613-620, 2000.

30. Larue L and Bellacosa A: Epithelial-mesenchymal transition in development and cancer: role of phosphatidylinositol 3' kinase/AKT pathways. Oncogene. 24: 7443-7454, 2005. 